\title{
Complication rates associated with open versus percutaneous pedicle screw instrumentation among patients undergoing minimally invasive interbody fusion for adult spinal deformity
}

\author{
Khoi D. Than, MD, ${ }^{1}$ Praveen V. Mummaneni, MD, ${ }^{4}$ Kelly J. Bridges, MD, ${ }^{1}$ Stacie Tran, MPH, ${ }^{2}$ \\ Paul Park, MD, ${ }^{3}$ Dean Chou, MD, ${ }^{4}$ Frank La Marca, MD, ${ }^{5}$ Juan S. Uribe, MD, ${ }^{6}$ Todd D. Vogel, MD, ${ }^{7}$ \\ Pierce D. Nunley, MD, ${ }^{8}$ Robert K. Eastlack, MD, ${ }^{9}$ Neel Anand, MD, ${ }^{10}$ David O. Okonkwo, MD, PhD, ${ }^{11}$ \\ Adam S. Kanter, MD, ${ }^{11}$ and Gregory M. Mundis Jr., MD, ${ }^{9}$ on behalf of the International Spine \\ Study Group
}

\begin{abstract}
${ }^{1}$ Department of Neurological Surgery, Oregon Health \& Science University, Portland, Oregon; ${ }^{2}$ San Diego Center for Spinal Disorders, La Jolla, California; ${ }^{3}$ Department of Neurosurgery, University of Michigan, Ann Arbor, Michigan; ${ }^{4}$ Department of Neurological Surgery, University of California, San Francisco, California; ${ }^{5}$ Department of Neurosurgery, Henry Ford Health System, Detroit, Michigan; ${ }^{6}$ Department of Neurosurgery, Barrow Neurological Institute, Phoenix, Arizona; ${ }^{7}$ Great Lakes Neurosurgical Associates, Grand Rapids, Michigan; ${ }^{8}$ Spine Institute of Louisiana, Shreveport, Louisiana; ${ }^{9}$ Division of Orthopaedic Surgery, Scripps Clinic Medical Group, La Jolla, California; ${ }^{10}$ Orthopedics, Cedars-Sinai Medical Center, Los Angeles, California; and ${ }^{11}$ Department of Neurological Surgery, University of Pittsburgh, Pennsylvania
\end{abstract}

OBJECTIVE High-quality studies that compare outcomes of open and minimally invasively placed pedicle screws for adult spinal deformity are needed. Therefore, the authors compared differences in complications from a circumferential minimally invasive spine (MIS) surgery and those from a hybrid surgery.

METHODS A retrospective review of a multicenter database of patients with spinal deformity who were treated with an MIS surgery was performed. Database inclusion criteria included an age of $\geq 18$ years and at least 1 of the following: a coronal Cobb angle of $>20^{\circ}$, a sagittal vertical axis of $>5 \mathrm{~cm}$, a pelvic incidence-lumbar lordosis angle of $>10^{\circ}$, and/or a pelvic tilt of $>20^{\circ}$. Patients were propensity matched according to the levels instrumented.

RESULTS In this database, a complete data set was available for 165 patients, and after those who underwent 3-column osteotomy were excluded, 137 patients were available for analysis; 76 patients remained after propensity matching (MIS surgery group 38 patients, hybrid surgery group 38 patients). The authors found no difference in demographics, number of levels instrumented, or preoperative and postoperative radiographic results. At least 1 complication was suffered by $55.3 \%$ of patients in the hybrid surgery group and $44.7 \%$ of those in the MIS surgery group $(p=0.359)$. Patients in the MIS surgery group had significantly fewer neurological, operative, and minor complications than those in the hybrid surgery group. The reoperation rates in both groups were similar. The most common complication category for the MIS surgery group was radiographic and for the hybrid surgery group was neurological. Patients in both groups experienced postoperative improvement in their Oswestry Disability Index and visual analog scale (VAS) back and leg pain scores (all $p<0.05$ ); however, MIS surgery provided a greater reduction in leg pain according to VAS scores.

CONCLUSIONS Overall complication rates in the MIS and hybrid surgery groups were similar. MIS surgery resulted in significantly fewer neurological, operative, and minor complications. Reoperation rates in the 2 groups were similar, and despite complications, the patients reported significant improvement in their pain and function.

https://thejns.org/doi/abs/10.3171/2017.8.FOCUS17479

KEY WORDS minimally invasive spine surgery; complications; transforaminal lumbar interbody fusion; lateral lumbar interbody fusion; adult spinal deformity; percutaneous instrumentation

ABBREVIATIONS ASD = adult spinal deformity; BMI = body mass index; CCA = coronal Cobb angle; EBL = estimated blood loss; $\mathrm{LL}=$ lumbar lordosis; $\mathrm{LLIF}=$ lateral lumbar interbody fusion; MIS = minimally invasive spine; $\mathrm{PI}=$ pelvic incidence; $\mathrm{PT}$ = pelvic tilt; SSI = surgical site infection; SVA = sagittal vertical axis; TLIF = transforaminal lumbar interbody fusion; UTI = urinary tract infection; VAS = visual analog scale.

SUBMITTED July 27, 2017. ACCEPTED August 24, 2017

INCLUDE WHEN CITING DOI: 10.3171/2017.8.FOCUS17479. 
$\mathrm{L}$ UMBAR fusion has been used to treat a variety of spinal pathologies, including tumors, trauma, infection, degenerative disease, and deformity. ${ }^{1,6,10,13,19,23}$ The use of lateral interbody techniques offers a number of advantages to the spine surgeon working on deformity from L-2 to L-5. Lateral access provides access to the entire disc space and enables placement of a larger implant, which facilitates greater indirect foraminal and central decompression and higher rates of arthrodesis. ${ }^{20}$ The ability to release the annulus fibrosus on either side of the vertebral body enables greater correction of coronal deformity than does a solely posterior approach.,24 Anterior and lateral approaches also enable anterior longitudinal ligament sectioning and anterior column release, which is a powerful technique for improving a patient's sagittal deformity. ${ }^{2-4,15,28}$ Lateral techniques use less invasive surgical portals, which results in small muscle-sparing incisions, reduced blood loss, and faster postoperative recovery and makes them important tools in a spine surgeon's armamentarium. . $11,14,16-18,22,26,29$

Lateral lumbar interbody fusion (LLIF) is generally supplemented with posterior fixation (e.g., pedicle screw placement), which can be performed via open or minimally invasive (percutaneous) techniques. The advantages conferred by open instrumentation include direct visualization of anatomical landmarks, the ability to decorticate bony surfaces easily to maximize posterolateral arthrodesis, and reduction of fluoroscopic radiation exposure to the patient and surgeon compared with that necessary during percutaneous fixation. In comparison, the advantages of minimally invasive techniques include less disruption to the paraspinal musculature and stabilizing structures, which results in decreases in blood loss, postoperative pain, length of hospital stay, and iatrogenic morbidity. 5,11,13,16-18,22,26,29

In this study, we aimed to retrospectively analyze a large multicenter database to determine the effect of open surgery on complications compared with that of using percutaneous screws among patients who underwent minimally invasive interbody fusion procedures with supplemental fixation for adult spinal deformity (ASD). ${ }^{25}$

\section{Methods}

\section{Study Design and Patient Population}

We performed a retrospective analysis of data collected from a multicenter database of patients with ASD who had been treated with a component of minimally invasive surgical techniques between 2009 and 2013. Eleven participating institutions contributed data, and each site obtained institutional review board approval. Inclusion criteria for entry into the multicenter database were patient age of $\geq$ 18 years and at least 1 of the following factors: a coronal Cobb angle (CCA) of $>20^{\circ}$, a sagittal vertical axis (SVA) of $>5 \mathrm{~cm}$, a pelvic tilt (PT) of $>20^{\circ}$, a pelvic incidencelumbar lordosis (PI-LL) angle of $>10^{\circ}$, and/or a thoracic kyphosis (TK) angle $\geq 60^{\circ}$. This database included patients treated with a component of minimally invasive surgery as part of their index surgery. Patients were categorized into 1 of 2 groups: those who underwent minimally invasive spine (MIS) surgery (MIS surgery group) or those who un- derwent hybrid surgery (hybrid surgery group). The MIS surgery group included patients who had undergone minimally invasive LLIF and/or transforaminal lumbar interbody fusion (TLIF) with percutaneous pedicle screw fixation. The hybrid surgery group consisted of patients who had undergone LLIF with open pedicle screw fixation. The surgical approach for each patient was determined at the discretion of the surgeon; all surgeons in this group perform both minimally invasive and hybrid spine surgeries. Data on decompressions (laminectomies, foraminotomies, etc.) and posterior column osteotomies performed were not collected, nor were data on radiation exposure.

Patients who underwent 3-column osteotomy as part of their open procedure were excluded from the study. In addition, patients who did not have a minimum of 2 years of follow-up were not included in the analysis. To ensure homogenous comparison groups, patients in the MIS and hybrid surgery groups were matched by levels treated.

An initial query of the multicenter database identified 97 patients who had undergone MIS surgery and 68 who had undergone hybrid surgery. Patients were propensity matched based on the number of levels treated, which resulted in a total of 76 patients analyzed, with 38 in each group (MIS and hybrid surgery groups). A flow diagram for patient selection is shown in Fig. 1.

\section{Data Collection}

Health-related quality of life measures were assessed at baseline and at the latest follow-up visit. Clinical outcome variables included Oswestry Disability Index (ODI) ${ }^{8}$ and visual analog scale (VAS) scores for both back and leg symptoms. Demographic and intraoperative data, including age, body mass index (BMI), estimated blood loss (EBL), operating room time, and number of levels treated, were also analyzed for each outcome group. Thirty-sixinch standing scoliosis radiographs at baseline and at least 2 years after surgery were available for each patient. Measured radiographic parameters included coronal curve, PI, LL, PI-LL mismatch, PT, and SVA. All radiographs were evaluated at a single location for consistency.

\section{Data and Statistical Analysis}

Means ( \pm standard deviation) were used to document continuous variables, and frequency analysis was used for categorical variables. Comparisons between the 2 outcome groups were performed using nonparametric MannWhitney U-test and chi-square analyses. Because not all data points were distributed normally, a nonparametric test was applied. Nonparametric tests can be applied to normally distributed data and are less sensitive to outliers than their parametric counterparts, which is important in comparisons of small samples. The change between preoperative and postoperative parameters within each group was analyzed using a paired Wilcoxon signed-rank test. A $p$ value of $\leq 0.05$ was considered significant.

\section{Results}

\section{Patient Population}

After excluding patients who underwent 3-column osteotomy and after propensity matching based on the 


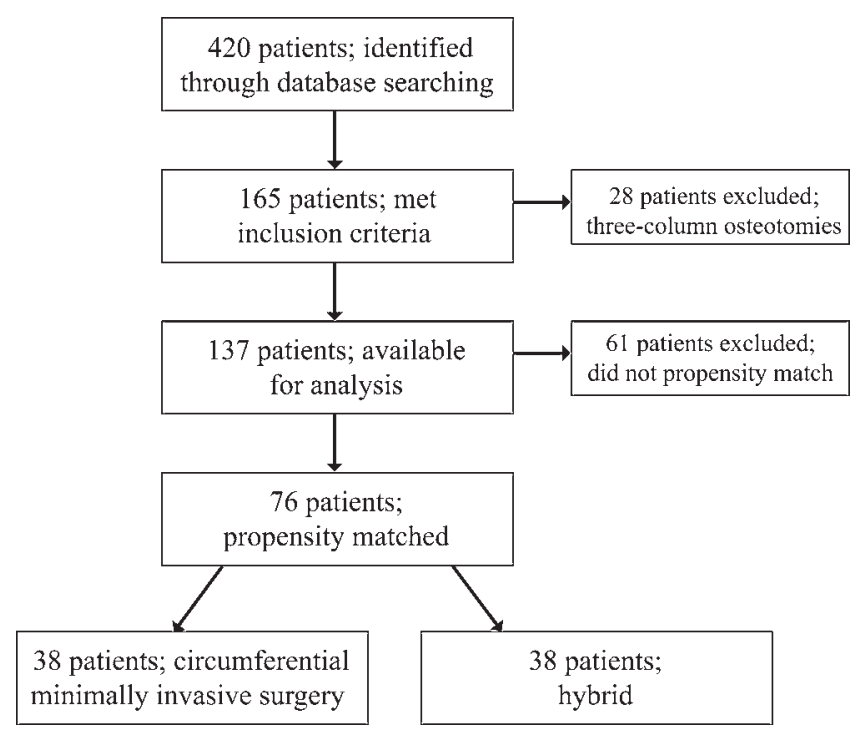

FIG. 1. Flow diagram for patient selection.

number of levels treated, 76 patients were included in this study for analysis (MIS surgery group 38 patients, hybrid surgery group 38 patients). Demographic, radiographic, operative, and clinical outcomes data are displayed in Table 1. Demographically, we found no significant difference between the MIS and hybrid surgery groups in mean age (62.8 vs 57.7 years, respectively; $\mathrm{p}=0.147)$, sex $(71.1 \%$ vs $86.8 \%$ female, respectively; $p=0.091)$, BMI (27.7 vs 26.2 , respectively; $\mathrm{p}=0.265)$, or smoking status $(5.3 \%$ vs $10.5 \%$, respectively; $\mathrm{p}=0.395$ ).

\section{Operative Outcomes}

We found no significant difference between the MIS and hybrid surgery groups in the number of levels instrumented ( 6.1 vs 6.8 , respectively; $p=0.622$ ), the percentage of patients who required pelvic fixation $(13.2 \%$ vs $21.1 \%$, respectively; $p=0.361$ ), or the percentage of patients who underwent staged procedures (i.e., anterior column and posterior column performed on different days) $(60.5 \%$ vs $52.6 \%$, respectively; $\mathrm{p}=0.488$ ). We also found no significant difference in the number of patients who underwent fusion or instrumentation at L5-S1. In the hybrid surgery group, 16 (42.1\%) patients underwent an interbody fusion at L5-S1, compared with $21(55.3 \%)$ patients in the MIS surgery group $(\mathrm{p}=0.251)$, and $23(60.5 \%)$ patients in the hybrid surgery group and $24(63.2 \%)$ patients in the MIS surgery group $(\mathrm{p}=0.813)$ had a construct that ended at $\mathrm{S}-1$ or below.

No significant difference was found in preoperative and postoperative PT, PI, PI-LL angle, SVA, or CCA between the groups.

Patients in the MIS surgery group had a lower EBL than those in the hybrid surgery group (673.7 vs 1359.5 $\mathrm{ml}$, respectively; $\mathrm{p}=0.001$ ), and operative time was shorter for patients in the MIS surgery group (490.2 vs 623.3 minutes, respectively; $p=0.015$ ). However, we found no significant difference between the 2 groups regarding the requirement for blood transfusion, average length of stay, or average follow-up duration.

TABLE 1. Clinical, radiographic, and outcome comparisons between the MIS and hybrid surgery groups using the Mann-Whitney U-test and chi-square test

\begin{tabular}{|c|c|c|c|}
\hline Data Type & $\begin{array}{c}\text { Hybrid Surgery } \\
\text { Group } \\
(n=38)\end{array}$ & $\begin{array}{c}\text { MIS Surgery } \\
\text { Group } \\
(n=38)\end{array}$ & $\begin{array}{c}p \\
\text { Value }\end{array}$ \\
\hline \multicolumn{4}{|l|}{ Demographics } \\
\hline Age (yrs) & $57.7 \pm 13.7$ & $62.8 \pm 9.2$ & 0.147 \\
\hline Sex, female & $33(86.8)$ & $27(71.1)$ & 0.091 \\
\hline Follow-up (mos) & $32 \pm 8.5$ & $35.1 \pm 9.6$ & 0.125 \\
\hline $\mathrm{BMI}\left(\mathrm{kg} / \mathrm{m}^{2}\right)$ & $26.2 \pm 5.8$ & $27.7 \pm 5.2$ & 0.265 \\
\hline Smoking & 4 (10.5) & $2(5.3)$ & 0.395 \\
\hline \multicolumn{4}{|l|}{ Surgical } \\
\hline Levels instrumented & $6.8 \pm 3.5$ & $6.1 \pm 2.6$ & 0.622 \\
\hline Staged & $20(52.6)$ & $23(60.5)$ & 0.488 \\
\hline Transfusion & $20(52.6)$ & $17(44.7)$ & 0.491 \\
\hline Pelvic fixation & 8 (21.1) & $5(13.2)$ & 0.361 \\
\hline L5-S1 interbody fusion & $16(42.1)$ & $21(55.3)$ & 0.251 \\
\hline $\begin{array}{l}\text { Construct ending at or } \\
\text { below S-1 }\end{array}$ & $23(60.5)$ & $24(63.2)$ & 0.813 \\
\hline \multicolumn{4}{|l|}{ Preop } \\
\hline $\mathrm{PT}\left({ }^{\circ}\right)$ & $22.4 \pm 10.4$ & $26.2 \pm 12.5$ & 0.32 \\
\hline $\mathrm{PI}\left({ }^{\circ}\right)$ & $52.6 \pm 14.4$ & $54 \pm 13.4$ & 0.762 \\
\hline PI-LL angle $\left({ }^{\circ}\right)$ & $15.1 \pm 18.4$ & $16.5 \pm 14.7$ & 0.646 \\
\hline $\operatorname{LL}\left({ }^{\circ}\right)$ & $37.5 \pm 19.0$ & $37.2 \pm 14.0$ & 0.25 \\
\hline SVA (mm) & $47.3 \pm 57.7$ & $47.6 \pm 47.1$ & 0.729 \\
\hline $\begin{array}{l}\text { Maximum Cobb } \\
\text { angle }\left({ }^{\circ}\right)\end{array}$ & $40.7 \pm 15.1$ & $36.7 \pm 14.4$ & 0.307 \\
\hline VAS score, back pain & $6.8 \pm 2.7$ & $6.4 \pm 2.3$ & 0.236 \\
\hline VAS score, leg pain & $5.5 \pm 3.2$ & $5.5 \pm 3.0$ & 0.96 \\
\hline ODI & $59.1 \pm 18.5$ & $46.6 \pm 16.5$ & $0.005^{*}$ \\
\hline \multicolumn{4}{|l|}{ Postop } \\
\hline $\mathrm{PT}\left({ }^{\circ}\right)$ & $22.7 \pm 11.3$ & $24.8 \pm 11.8$ & 0.574 \\
\hline $\mathrm{PI}\left({ }^{\circ}\right)$ & $53.1 \pm 14.3$ & $54.2 \pm 12.5$ & 0.854 \\
\hline PI-LL angle $\left({ }^{\circ}\right)$ & $9.7 \pm 18.6$ & $9.2 \pm 13.1$ & 0.858 \\
\hline $\operatorname{LL}\left({ }^{\circ}\right)$ & $43.4 \pm 15.1$ & $45.6 \pm 12.4$ & 0.707 \\
\hline SVA (mm) & $49.4 \pm 59.8$ & $48.2 \pm 55.2$ & 0.94 \\
\hline $\begin{array}{l}\text { Maximum Cobb } \\
\text { angle }\left({ }^{\circ}\right)\end{array}$ & $18.3 \pm 22.2$ & $9.5 \pm 15.0$ & 0.111 \\
\hline VAS score, back pain & $4.2 \pm 2.8$ & $2.9 \pm 2.6$ & $0.037^{*}$ \\
\hline VAS score, leg pain & $2.8 \pm 2.8$ & $1.8 \pm 2.2$ & 0.136 \\
\hline ODI & $38.3 \pm 20.7$ & $25.9 \pm 17.9$ & $0.005^{*}$ \\
\hline \multicolumn{4}{|l|}{ Operative } \\
\hline $\mathrm{EBL}(\mathrm{ml})$ & $1359.5 \pm 1024.9$ & $673.7 \pm 555.4$ & $0.001^{*}$ \\
\hline $\begin{array}{l}\text { Operating room } \\
\text { time (mins) }\end{array}$ & $623.3 \pm 232.5$ & $490.2 \pm 214.6$ & $0.015^{*}$ \\
\hline Length of stay (days) & $8.7 \pm 5.3$ & $7.7 \pm 5.1$ & 0.183 \\
\hline
\end{tabular}


TABLE 2. Comparison of complication rates in the MIS and hybrid surgery groups

\begin{tabular}{lccc}
\hline \multirow{2}{*}{ Complication } & \multicolumn{2}{c}{ No. of Complications (\%) } & \\
\cline { 2 - 3 } & $\begin{array}{c}\text { Hybrid Surgery } \\
\text { Group }(\mathrm{n}=38)\end{array}$ & $\begin{array}{c}\text { MIS Surgery } \\
\text { Group }(\mathrm{n}=38)\end{array}$ & $\begin{array}{c}\mathrm{p} \\
\text { Value }\end{array}$ \\
\hline Total & $21(55.3)$ & $17(44.7)$ & 0.359 \\
\hline Reoperation & $11(28.9)$ & $10(26.3)$ & 0.798 \\
\hline Major complication & $14(36.8)$ & $11(28.9)$ & 0.464 \\
\hline Minor complication & $19(50.0)$ & $10(26.3)$ & $0.034^{*}$ \\
\hline Neurological & $11(28.9)$ & $4(10.5)$ & $0.044^{*}$ \\
\hline Operative complication & $7(18.4)$ & $0(0.0)$ & $0.005^{*}$ \\
\hline Other & $1(2.6)$ & $1(2.6)$ & 0.999 \\
\hline Perioperative complication & $5(13.2)$ & $1(2.6)$ & 0.089 \\
\hline Postoperative complication & $19(50.0)$ & $15(39.5)$ & 0.356 \\
\hline$*$ Signifinnnn
\end{tabular}

* Significant result.

\section{Clinical Outcomes}

No significant difference between preoperative and postoperative VAS leg pain scores was found between the study groups. However, we did find a statistically significant improvement in VAS back pain scores in the MIS surgery group compared with that in the hybrid surgery group (2.9 vs 4.2 , respectively; $\mathrm{p}=0.037$ ), even though both groups started with similar values (6.4 vs 6.8 , respectively; $\mathrm{p}=0.236$ ). The postoperative ODI was lower in the MIS surgery group than in the hybrid surgery group (25.9 vs 38.3 , respectively; $p=0.005$ ). However, the preoperative ODI was also lower in the MIS surgery group than in the hybrid surgery group (46.6 vs 59.1, respectively; $p=$ $0.005)$. The changes between the preoperative and postoperative status in ODI were similar between groups (20.8 [hybrid surgery group] vs 20.7 [MIS surgery group]).

\section{Complication Rates}

Complication rates are detailed in Table 2. We found no statistically significant difference in the numbers of overall, major, radiographic, cardiac, gastrointestinal, perioperative, or postoperative complications between the MIS and hybrid surgery groups. There was also no difference in the numbers of reoperations, implant failures, or surgical site complications, which included dehiscence, erythema, drainage, hematoma, and seroma.

Six $(15.8 \%)$ patients in the hybrid surgery group suffered 9 incidental radiographic complications, whereas $10(26.3 \%)$ patients in the MIS surgery group suffered 12 radiographic complications. The radiographic complications in the MIS surgery group included distal junctional kyphosis, proximal junctional kyphosis, and pseudarthrosis. The radiographic complications in the hybrid surgery group included the same 3 complications and adjacentsegment disease and sagittal imbalance.

The MIS surgery group experienced fewer minor complications ( $26.3 \%$ vs $50.0 \%$, respectively; $\mathrm{p}=0.034)$, neurological complications $(10.5 \%$ vs $28.9 \%$, respectively; $\mathrm{p}$ $=0.044)$, and operative complications $(0.0 \%$ vs $18.4 \%$, respectively; $p=0.05$ ) than the hybrid surgery group (Table
TABLE 3. Comparison of minor complication rates in the MIS and hybrid surgery groups

\begin{tabular}{|c|c|c|}
\hline \multirow[b]{2}{*}{ Minor Complication } & \multicolumn{2}{|c|}{$\begin{array}{c}\text { No. of } \\
\text { Complications (\%) }\end{array}$} \\
\hline & $\begin{array}{l}\text { Hybrid } \\
\text { Surgery } \\
\text { Group } \\
(n=38)\end{array}$ & $\begin{array}{c}\text { MIS } \\
\text { Surgery } \\
\text { Group } \\
(n=38)\end{array}$ \\
\hline Infection, UTI & $4(10.5)$ & $0(0.0)$ \\
\hline Implant, painful & $2(5.3)$ & $0(0.0)$ \\
\hline Implant, prominence & $2(5.3)$ & $0(0.0)$ \\
\hline Implant, screw-bone interface loosening & $3(7.9)$ & $4(10.5)$ \\
\hline Radiographic, screw malposition & $0(0.0)$ & $1(2.6)$ \\
\hline Radiographic, adjacent-segment degeneration & $1(2.6)$ & $1(2.6)$ \\
\hline Radiographic, DJK w/o symptoms & $1(2.6)$ & $0(0.0)$ \\
\hline Radiographic, PJK w/o symptoms & $0(0.0)$ & $1(2.6)$ \\
\hline Surgical site, dehiscence & $0(0.0)$ & $0(0.0)$ \\
\hline Neurological, femoral cutaneous neuralgia & $0(0.0)$ & $1(2.6)$ \\
\hline Neurological, sensory deficit & $4(10.5)$ & $1(2.6)$ \\
\hline Neurological, pain/radiculopathy & $8(21.1)$ & $1(2.6)$ \\
\hline Cardiological, plural effusion & $1(2.6)$ & $1(2.6)$ \\
\hline Gastrointestinal tract, ileus & $1(2.6)$ & $1(2.6)$ \\
\hline Operative, dural tear & $3(7.9)$ & $0(0.0)$ \\
\hline Operative, vertebral body fracture & $2(5.3)$ & $0(0.0)$ \\
\hline
\end{tabular}

DJK = distal junctional kyphosis; $\mathrm{PJK}=$ proximal junctional kyphosis; $\mathrm{UTI}=$ urinary tract infection.

3). Neurological complications included cerebrovascular accident/stroke, femoral cutaneous neuralgia, motor paralysis, sensory deficit, and pain/radiculopathy. Operative complications included retained sponge/instrument, vascular injury, visceral injury, dural tear, fixation failure (hook/screw), implant failure, pedicle fracture, posterior element fracture, and vertebral body fracture.

We found a strong trend toward decreased perioperative and intraoperative complications in the MIS surgery group (2.6\% [MIS surgery group] vs $13.2 \%$ [hybrid surgery group]; $p=0.089$ ); however, these data did not reach statistical significance, likely because of the low patient numbers within each group. An identical trend toward fewer infections in the MIS surgery group than in the hybrid surgery group ( $2.6 \%$ vs $13.2 \%$, respectively; $\mathrm{p}=$ 0.089) was found, but the number of affected patients might have left the analysis insufficiently powered for the trend to reach significance. Infections tracked for these groups included deep infection, pneumonia, sepsis, superficial infection, and urinary tract infection (UTI).

Seven patients in the hybrid surgery group suffered an operative complication, which included 3 dural tears, 2 vertebral body fractures, 1 incisional hernia, and 1 case of excessive blood loss (> $4 \mathrm{~L})$. No operative complications were identified in the MIS surgery group $(p=0.005)$.

\section{Discussion}

In this study, we compared the complication profiles 
of patients who underwent hybrid surgery for ASD (LLIF with open posterior instrumentation) with those who underwent circumferential MIS surgery (minimally invasive LLIF and/or minimally invasive TLIF with percutaneous posterior instrumentation). In these well-matched groups, we found that patients in the MIS surgery group experienced fewer minor complications, neurological complications, and operative complications than those in the hybrid surgery group. Patients in the MIS surgery group also experienced shorter operative time and less blood loss. We found no statistically significant difference in the numbers of major complications, reoperations, implant failures, or surgical site complications between the 2 groups. To our knowledge, this is the first study to have examined the difference in complication rates between MIS surgery and hybrid surgery in patients with ASD.

A paucity of studies exist in the literature that compared complications between open and minimally invasive fusion surgery for ASD. Previous work has compared complications in patients with ASD treated via open surgery, hybrid surgery, or MIS surgery after propensity matching the groups for age, preoperative SVA, number of levels fused, and lumbar CCA. ${ }^{27}$ The authors found that blood loss was significantly lower in the MIS surgery group than in the open-surgery group (669 vs $2322 \mathrm{ml}$, respectively; $\mathrm{p}=0.001)$. No difference was found in the total, postoperative, or major complication rates among the 3 surgery groups. However, there were decreases in the numbers of intraoperative complications experienced during MIS and hybrid surgeries (0\% [MIS], 5.3\% [hybrid], and 25\% [open]; $p<0.03$ ). Our study had similar findings and the additional advantage of propensity matching according to number of levels.

A small number of systematic reviews have compared complication rates associated with open and minimally invasive TLIFs. Khan et al. ${ }^{12}$ performed a meta-analysis of 30 studies and found minimally invasive TLIF to result in statistically significantly less blood loss, shorter lengths of stay, and fewer complications than open TLIF. Goldstein et al. ${ }^{9}$ similarly analyzed 26 studies and found that patients who underwent minimally invasive surgery were less likely than those who underwent open surgery to experience medical adverse events (risk ratio $0.39,95 \%$ confidence interval $0.23-0.69, \mathrm{p}=0.001$ ) but not surgical adverse events. Medical adverse events included UTI, respiratory complications, cardiac complications, and need for transfusion. Patients who underwent minimally invasive surgery had statistically significantly less blood loss, faster times to ambulation, and shorter lengths of stay. Last, in a study that lacked adequate statistical analysis, Hu et al. ${ }^{11}$ systematically reviewed 14 studies and also found lower complication rates associated with minimally invasive TLIF than with open TLIF (11.87\% vs $14.35 \%$, respectively).

Two studies reported that surgical site infection (SSI) rates were lower after minimally invasive TLIF than after open TLIF. In a literature review, Parker et al. ${ }^{21}$ compared 10 cohorts of patients who underwent minimally invasive TLIF (362 patients) with 20 cohorts of patients who underwent open TLIF (1133 patients) and found a significantly lower incidence of SSI in the MIS surgery group (0.6\% vs $4.0 \%, p=0.0005)$. In a retrospective review of a large administrative database, McGirt et al. ${ }^{16}$ identified 5173 patients who underwent 1- or 2-level open or minimally invasive posterior lumbar fusion. Although the incidences of SSI and associated costs were similar in those who underwent 1-level minimally invasive fusion and those who underwent open fusion, the authors found significant differences when they compared 2-level fusions. Specifically, the incidence of SSI was $4.6 \%$ in their MIS surgery group and $7.0 \%$ in their open-surgery group $(p=0.037)$, and the mean SSI-associated cost per fusion was also lower in their MIS surgery group ( $\$ 756$ vs $\$ 1140$, respectively; $p$ $=0.030$ ).

The infection rates in our study were $2.6 \%$ in the MIS surgery group and $13.2 \%$ in the hybrid surgery group, and the average number of levels instrumented in both groups was greater than 6 , substantially more than that found in the 1- and 2-level fusion studies previously reported.

\section{Study Limitations}

This study's primary limitations were its retrospective design and the data review of a relatively small number of patients from a multicenter study. The retrospective nature limited the level of available detail, such as the costs, specific decompressions, and/or osteotomies performed in each group. The multicenter nature of the study introduced a level of variability that is difficult to control for with respect to data collection but provides more generalizable results. Because of the lower number of patients in each group, we were unable to achieve the gold standard $80 \%$ power. Because this was a multicenter study, we attempted to enroll as many patients with ASD who were undergoing minimally invasive correction as possible. However, because of the specific inclusion criteria and creation of homogenous cohorts for the 2 procedure types, our sample size decreased significantly. In addition, because 10 institutions contributed for the total of 76 patients in the propensity-matched cohort, we had insufficient power to determine statistical differences in the complication rates among institutions.

The results of this study improve our current understanding of complications after spine surgery. Future prospective studies that involve larger numbers of patients will help support and confirm the findings presented here.

\section{Conclusions}

In this study, 76 patients who underwent either MIS or hybrid surgery were followed up for at least 2 years, and we retrospectively compared their surgical outcomes. Overall complication rates between the MIS and hybrid surgery groups were similar. MIS surgery resulted in significantly fewer neurological, operative, and minor complications. Reoperation rates were similar, and despite complications, the patients reported significant improvement in their pain and function. Although the results of this study provide insight into complications after spine surgery, the paucity of studies from the literature that compared complications between these groups and the relatively small number of patients in our multicenter database reveal a need for future prospective studies that involve larger numbers of patients to support and confirm the findings presented here. 


\section{References}

1. Cho DC, Sung JK: Palliative surgery for metastatic thoracic and lumbar tumors using posterolateral transpedicular approach with posterior instrumentation. Surg Neurol 71:424433, 2009

2. Demirkiran G, Theologis AA, Pekmezci M, Ames C, Deviren V: Adult spinal deformity correction with multi-level anterior column releases: description of a new surgical technique and literature review. Clin Spine Surg 29:141-149, 2016

3. Deukmedjian AR, Dakwar E, Ahmadian A, Smith DA, Uribe JS: Early outcomes of minimally invasive anterior longitudinal ligament release for correction of sagittal imbalance in patients with adult spinal deformity. Sci World J 2012:789698, 2012

4. Deukmedjian AR, Le TV, Baaj AA, Dakwar E, Smith DA, Uribe JS: Anterior longitudinal ligament release using the minimally invasive lateral retroperitoneal transpsoas approach: a cadaveric feasibility study and report of 4 clinical cases. J Neurosurg Spine 17:530-539, 2012

5. Dhall SS, Wang MY, Mummaneni PV: Clinical and radiographic comparison of mini-open transforaminal lumbar interbody fusion with open transforaminal lumbar interbody fusion in 42 patients with long-term follow-up. J Neurosurg Spine 9:560-565, 2008

6. DiPaola CP, Molinari RW: Posterior lumbar interbody fusion. J Am Acad Orthop Surg 16:130-139, 2008

7. Dorward IG, Lenke LG, Bridwell KH, O'Leary PT, Stoker GE, Pahys JM, et al: Transforaminal versus anterior lumbar interbody fusion in long deformity constructs: a matched cohort analysis. Spine (Phila Pa 1976) 38:E755-E762, 2013

8. Fairbank JC, Pynsent PB: The Oswestry Disability Index. Spine (Phila Pa 1976) 25:2940-2952, 2000

9. Goldstein CL, Macwan K, Sundararajan K, Rampersaud YR: Perioperative outcomes and adverse events of minimally invasive versus open posterior lumbar fusion: meta-analysis and systematic review. J Neurosurg Spine 24:416-427, 2016

10. Grimm BD, Leas DP, Poletti SC, Johnson DR II: Postoperative complications within the first year after extreme lateral interbody fusion: experience of the first 108 patients. Clin Spine Surg 29:E151-E156, 2016

11. Hu W, Tang J, Wu X, Zhang L, Ke B: Minimally invasive versus open transforaminal lumbar fusion: a systematic review of complications. Int Orthop 40:1883-1890, 2016

12. Khan NR, Clark AJ, Lee SL, Venable GT, Rossi NB, Foley KT: Surgical outcomes for minimally invasive vs open transforaminal lumbar interbody fusion: an updated systematic review and meta-analysis. Neurosurgery 77:847-874, 2015

13. Kimura I, Shingu H, Murata M, Hashiguchi H: Lumbar posterolateral fusion alone or with transpedicular instrumentation in L4--L5 degenerative spondylolisthesis. J Spinal Disord 14:301-310, 2001

14. Lucio JC, Vanconia RB, Deluzio KJ, Lehmen JA, Rodgers JA, Rodgers W: Economics of less invasive spinal surgery: an analysis of hospital cost differences between open and minimally invasive instrumented spinal fusion procedures during the perioperative period. Risk Manag Healthc Policy 5:65-74, 2012

15. Manwaring JC, Bach K, Ahmadian AA, Deukmedjian AR, Smith DA, Uribe JS: Management of sagittal balance in adult spinal deformity with minimally invasive anterolateral lumbar interbody fusion: a preliminary radiographic study. $\mathbf{J}$ Neurosurg Spine 20:515-522, 2014

16. McGirt MJ, Parker SL, Lerner J, Engelhart L, Knight T, Wang MY: Comparative analysis of perioperative surgical site infection after minimally invasive versus open posterior/ transforaminal lumbar interbody fusion: analysis of hospital billing and discharge data from 5170 patients. J Neurosurg Spine 14:771-778, 2011
17. Moller DJ, Slimack NP, Acosta FL Jr, Koski TR, Fessler RG, Liu JC: Minimally invasive lateral lumbar interbody fusion and transpsoas approach-related morbidity. Neurosurg Focus 31(4):E4, 2011

18. Ntoukas V, Müller A: Minimally invasive approach versus traditional open approach for one level posterior lumbar interbody fusion. Minim Invasive Neurosurg 53:21-24, 2010

19. Okuda S, Miyauchi A, Oda T, Haku T, Yamamoto T, Iwasaki M: Surgical complications of posterior lumbar interbody fusion with total facetectomy in 251 patients. J Neurosurg Spine 4:304-309, 2006

20. Ozgur BM, Aryan HE, Pimenta L, Taylor WR: Extreme Lateral Interbody Fusion (XLIF): a novel surgical technique for anterior lumbar interbody fusion. Spine J 6:435-443, 2006

21. Parker SL, Adogwa O, Witham TF, Aaronson OS, Cheng J, McGirt MJ: Post-operative infection after minimally invasive versus open transforaminal lumbar interbody fusion (TLIF): literature review and cost analysis. Minim Invasive Neurosurg 54:33-37, 2011

22. Peng CWB, Yue WM, Poh SY, Yeo W, Tan SB: Clinical and radiological outcomes of minimally invasive versus open transforaminal lumbar interbody fusion. Spine (Phila Pa 1976) 34:1385-1389, 2009

23. Pu X, Zhou Q, He Q, Dai F, Xu J, Zhang Z, et al: A posterior versus anterior surgical approach in combination with debridement, interbody autografting and instrumentation for thoracic and lumbar tuberculosis. Int Orthop 36:307-313, 2012

24. Rothenfluh DA, Koenig M, Stokes OM, Behrbalk E, Boszczyk BM: Access-related complications in anterior lumbar surgery in patients over 60 years of age. Eur Spine J 23 (Suppl 1):S86-S92, 2014

25. Than KD, Nguyen S, Park P, Chou D, La Marca F, Uribe JS, et al: What is the effect of open vs percutaneous screws on complications among patients undergoing lateral interbody fusion for adult spinal deformity? Neurosurgery 63 (Suppl 1):166, 2016 (Abstract 165)

26. Tsutsumimoto T, Shimogata M, Ohta H, Misawa H: Mini-open versus conventional open posterior lumbar interbody fusion for the treatment of lumbar degenerative spondylolisthesis: comparison of paraspinal muscle damage and slip reduction. Spine (Phila Pa 1976) 34:1923-1928, 2009

27. Uribe JS, Deukmedjian AR, Mummaneni PV, Fu KM, Mundis GM Jr, Okonkwo DO, et al: Complications in adult spinal deformity surgery: an analysis of minimally invasive, hybrid, and open surgical techniques. Neurosurg Focus 36(5):E15, 2014

28. Uribe JS, Smith DA, Dakwar E, Baaj AA, Mundis GM, Turner AWL, et al: Lordosis restoration after anterior longitudinal ligament release and placement of lateral hyperlordotic interbody cages during the minimally invasive lateral transpsoas approach: a radiographic study in cadavers. J Neurosurg Spine 17:476-485, 2012

29. Youssef JA, McAfee PC, Patty CA, Raley E, DeBauche S, Shucosky E, et al: Minimally invasive surgery: lateral approach interbody fusion: results and review. Spine (Phila Pa 1976) 35 (26 Suppl):S302-S311, 2010

\section{Disclosures}

Dr. Anand has direct ownership of stock in Globus Medical and Medtronic, is a patent owner (Medtronic), and has received royalty payments from Globus Medical. Dr. Chou has served as a consultant for Medtronic and Globus. Dr. Eastlack has direct ownership of stock in NuVasive, SeaSpine, and Alphatec Spine; has served as a consultant for NuVasive, Alphatec, Titan, Aesculap, SeaSpine, and K2M; is a patent holder (Invuity, Globus, Spine Innovation, and NuTech); and is part owner of Spine Innovation. 
Dr. Kanter is a patent holder (Zimmer Biomet) and has served as a consultant for NuVasive. Dr. La Marca has served as a consultant for Globus Medical, Zimmer, DePuy Synthes, and RTI and has received royalty payments from Globus Medical and Zimmer. Dr. Mummaneni has served as a consultant for DePuy Spine and Stryker; has direct ownership of stock in Spinicity/ISD; has provided statistical analysis for study/writing or editorial assistance on manuscripts for ISSG; has received royalty payments from DePuy Spine, Thieme Publishing, and Springer Publishing; and has received honoraria from AOSpine and Globus. Dr. Mundis has served as a consultant for NuVasive, AlloSource, and K2M. Dr. Nunley has direct ownership of stock in Amedica, Paradigm, and Spineology; is a patent holder (K2M and LDR Spine); has served as a consultant for $\mathrm{K} 2 \mathrm{M}$; and has served on the speakers' bureau for K2M and LDR Spine. Dr. Park has served as a consultant for Globus, Medtronic, NuVasive, Biomet Zimmer, and Bioventus and has received royalty payments from Globus. Dr. Uribe has served as a consultant for NuVasive.

\section{Author Contributions}

Conception and design: Than, Mummaneni, Tran, Park, Chou, La Marca, Uribe, Vogel, Nunley, Eastlack, Anand, Okonkwo, Kanter, Mundis. Acquisition of data: Than, Mummaneni, Park, Chou, La Marca, Uribe, Vogel, Nunley, Eastlack, Anand, Okonkwo, Kanter, Mundis. Analysis and interpretation of data: all authors. Drafting the article: Than, Bridges. Critically revising the article: all authors. Reviewed submitted version of manuscript: all authors. Approved the final version of the manuscript on behalf of all authors: Than. Statistical analysis: Tran. Administrative/technical/ material support: Tran. Study supervision: Mummaneni, Mundis.

\section{Correspondence}

Khoi D. Than, Department of Neurological Surgery, Mail Code CH8N, Oregon Health \& Science University, 3303 SW Bond Ave., Portland, OR 97239. email: thank@ohsu.edu. 